TITLE:

\title{
Finite-element analysis of laminated rubber bearing of building frame under seismic excitation
}

\section{$\operatorname{AUTHOR}(S)$ :}

Ohsaki, Makoto; Miyamura, Tomoshi; Kohiyama, Masayuki; Yamashita, Takuzo; Yamamoto, Masashi; Nakamura, Naohiro

\section{CITATION:}

Ohsaki, Makoto ... [et al]. Finite-element analysis of laminated rubber bearing of building frame under seismic excitation. Earthquake Engineering \& Structural Dynamics 2015, 44(11): 1881-1898

\section{ISSUE DATE:}

2015-09

URL:

http://hdl.handle.net/2433/217068

\section{RIGHT:}

This is the accepted version of the following article: [Ohsaki, M., Miyamura, T., Kohiyama, M., Yamashita, T., Yamamoto, M., and Nakamura, N. (2015) Finite-element analysis of laminated rubber bearing of building frame under seismic excitation. Earthquake Engng Struct. Dyn., 44: 1881-1898. ], which has been published in final form at http://dx.doi.org/10.1016/j.jisolstr.2015.06.020. This article may be used for non-commercial purposes in accordance with Wiley Terms and Conditions for Self-Archiving.; This is not the published version. Please cite only the published version.; この論文は出版社版でありません。引用の際には出版社版をご確認ご利用ください。 


\title{
Finite-Element Analysis of Laminated Rubber Bearing of Building Frame under Seismic Excitation
}

\author{
${\text { Makoto Ohsaki }{ }^{1 *} \text {, Tomoshi Miyamura }}^{2,3}$, Masayuki Kohiyama ${ }^{4}$, \\ Takuzo Yamashita ${ }^{3}$, Masashi Yamamoto ${ }^{5}$ and Naohiro Nakamura ${ }^{5}$ \\ ${ }^{1 *}$ Department of Architecture, Hiroshima University, 1-4-1 Kagamiyama, \\ Higashi-Hiroshima 739-8527, Japan, ohsaki@hiroshima-u.ac.jp \\ ${ }^{2}$ Department of Computer Science, Nihon University, 1 Nakagawara, \\ Tokusada, Tamura, Koriyama 963-8642, Japan \\ ${ }^{3}$ Hyogo Earthquake Engineering Research Center, National Research Institute for Earth Science \\ and Disaster Prevention, 1501-21 Nishikameyama, Mitsuta, Shijimi, Miki 673-0515, Japan \\ ${ }^{4}$ Department of System Design Engineering, Keio University, \\ 3-14-1 Hiyoshi, Kohoku, Yokohama 223-8522, Japan \\ ${ }^{5}$ Takenaka Research \& Development Institute, 1-5-1 Ohtsuka, Inzai 270-1395, Japan
}

\section{SUMMARY}

Finite element analysis is carried out for a building frame supported by laminated rubber bearings to simultaneously investigate global displacement and local stress responses under seismic excitation. The frame members as well as the rubber bearings are discretized into hexahedral solid elements with more than 3 million degrees of freedom. The material property of rubber is represented by the Ogden model, and the frame is assumed to remain in elastic range. It is shown that the time histories of non-uniform stress distribution and rocking behavior of the rubber bearings under a frame subjected to seismic excitation can be successfully evaluated, and detailed responses of base and frame can be evaluated through large-scale finite element analysis.

KEY WORDS: natural rubber bearing, finite element analysis, base isolation, seismic response, hyper-elasticity, parallel computing. 
M. Ohsaki et al.

\section{INTRODUCTION}

A project called Earthquake Simulator (E-Simulator) is underway at the Hyogo Earthquake Engineering Research Center (E-Defense), which belongs to the National Research Institute for Earth Science and Disaster Prevention (NIED), Japan. The E-Defense has the world's largest shaking table to conduct tests of full-scale frames under seismic motions. The platform of the E-Simulator is a parallel finite element (FE) analysis software package called ADVENTURECluster (ADVC) [1,2], which utilizes the Coarse Grid Conjugate Gradient (CGCG) method developed by Suzuki et al. [3] and Akiba et al. [4]. The ADVENTURECluster/E-Simulator has basic functions that are required for a general-purpose FE-analysis code.

One of the purposes of shake-table tests at the E-Defense is to validate simulation codes including the E-Simulator developed in NIED. Using the E-Simulator, we can carry out largescale analysis of a building frame with a very fine mesh of solid elements, e.g., a superhighrise steel building frame model with more than 70 million degrees of freedom [5, 6], after identification of the material properties only from a simple material test. The accuracy of the analysis code is verified using the full-scale shake-table test results of a four-story steel building frame [7] and a composite beam under cyclic loading [8]. Using the E-Simulator, global and local responses of building frames under seismic excitation can be simulated without resort to any macro model.

Extensive research has been carried out for modeling mechanical properties and simulating large-deformation cyclic responses of laminated rubber bearings [9-11]. The simplest model is the one-dimensional bilinear model that has been successfully applied to investigate global behavior of base-isolated building frames under seismic excitation [12]. The effect of vertical pressure and horizontal displacement on the mechanical property is to be appropriately incorporated for accurate estimation of responses using a simple model. More complex onedimensional models have also been proposed. Abe et al. [13] combined elastoplastic and nonlinear elastic springs as well as friction element. Kalpakidis et al. [14] considered the effect of increase of temperature on the mechanical property of a lead rubber bearing. Yamamoto et al. [15] developed a two dimensional model for high-damping rubber bearings.

It is known that a laminated rubber bearing under compression collapses due to buckling when subjected to large horizontal deformation. Takaoka et al. [16] investigated the ultimate behavior of a base-isolated structure by carrying out a shake-table test. Kikuchi et al. [17] proposed a multiple shear spring model for three-dimensional analysis. Kelly and Konstantinidis [18] investigated detailed behavior, including buckling and friction, using analytical and numerical approaches. Since the stress distribution in the rubber is not uniform in large deformation range, it is very important to investigate local deformation for accurate simulation of the ultimate behavior. It is well known that local tensile stress may exist even when the total reaction force of its rubber bearing indicates compression. However, only global behavior such as load-displacement relation can be obtained from experimental study or simulation using a simplified model. Dependency of horizontal stiffness on vertical stress has been studied in relation to buckling under vertical pressure and horizontal loads [19, 20]. Koh and Kelly [21] presented a two-degree-of-freedom model taking into account the flexural deformation as well as shear deformation to evaluate lateral stiffness under vertical pressure. However, the variation of horizontal stiffness of a base attached to frame has not been fully investigated using time-history analysis.

By contrast, the local behavior such as stress distribution can be precisely investigated using an FE-analysis. Analysis of a structural component composed of elastomeric material is very difficult because of its hyper-elastic property. Several material models have been 
presented for elastomers [22-25]. In this study, the hyper-elastic constitutive relation of natural rubber is modeled using the Ogden model [26], which is more general than the Mooney-Ryvlin model and Neo-Hookean model. Matsuda et al. [27] investigated vertical and lateral stiffnesses of a rubber bearing using FE-analysis with the Neo-Hookean model. Gracia et al. [28] developed an overlay model for simulating hyper-elastic and viscoelastic behavior. Lejeunes et al. [29] presented a numerical reduction model to reduce the computational cost for a thin rubber sheet. Ali and Abdel-Ghaffar [30] used the Hart-Smith model [31] of elastic material with a logarithmic penalty function for incorporating incompressibility. They carried out FE-analysis to develop a simplified model for seismic response analysis of a base-isolated bridge. Matsuda [32] developed a mixed displacement/pressure FE-model for analysis of natural rubber bearing under vertical pressure and shear. Cardone et al. [33] carried out three-dimensional FE-analysis to show that the air temperature has substantial effect on the stiffness of rubber bearing.

Properties of elastomers are also investigated extensively for application to fiber reinforced elastomeric isolators (FREIs) [34]. Toopchi-Nezhad et al. [35] used the Neo-Hookean model for FE-analysis of FREI. Osgooei et al. [36] investigated horizontal load-displacement relation and vertical stress distribution of unbonded square FREI under monotonic loading in different directions. They used three dimensional solid elements with Neo-Hookeam model, and showed that the loading in the diagonal direction leads to the maximum stiffness. Warn et al. [37] presented an overlapping area method for estimation of the critical load of laminated rubber bearing. The FE-model was verified by $3 \mathrm{D}$ analysis using the Ogden model, and a $2 \mathrm{D}$ FE-analysis with the Neo-Hookean model and plane strain elements was carried out for parametric evaluation of responses. Osgooei et al. [38] investigated vertical response properties of FREIs using parametric 3D FE-analysis. They demonstrated good agreement of stress distributions between those obtained by FE-analysis and analytical formula, and carried out seismic response analysis of a liquid storage tank. Mordini and Stauss [39] investigated properties of an FREI consisting of high-damping rubber and glass fiber layers. The Ogden model is used for static analysis and the Neo-Hookean model is used for dynamic analysis. Good agreement is observed between $2 \mathrm{D}$ and $3 \mathrm{D}$ analysis results, and a simple onedimensional model is presented using linear spring and linear damper. Das et al. [40] carried out 3D FE-analysis of FREIs to investigate effect of loading directions on responses under cyclic hrizontal loads. The rubber material is represented by the Ogden model for hyperelasticity and the Prony seris for viscoelasticity.

In contrast to FE-analysis of elastomeric isolators, seismic response of a base-isolated building frame is usually investigated using a simplified model of isolator. Cardone et al. [41] investigated elastoplastic responses of an RC frame using empirical hysteresis models for lead rubber bearing and high-damping rubber bearing. Gur et al. [42] compared seismic responses of buildings isolated using shape-memory alloy rubber bearing and lead rubber bearing, where one-dimensional models are used for modeling isolators. Salomón [43] carried out seismic response analysis of a six-story plane frame using plane stress elements for the rubber bearing.

In this study, we carry out FE-analysis of a base-isolated frame to investigate deformation and stress distribution of rubber bearings under a severe earthquake ground motion. Natural rubber bearings are attached at the base of a 10-story $\mathrm{RC}$ frame. The rubber sheets and steel plates are discretized into linear hexahedral solid elements, and the ADVENTURECluster/ESimulator is used for simulation with a PC that has multiple CPUs and cores. Horizontal seismic motions are applied to the base-isolated frame, and the time histories of interaction between the base and the rubber bearing as well as the complex local response of the isolator is investigated. 


\section{LAMINATED RUBBER BEARING MODEL}

Consider a laminated rubber bearing model as shown in Figure 1. The radius of rubber is $350 \mathrm{~mm}$, and there exists a hole with the radius $7.5 \mathrm{~mm}$ at the center. Therefore, the area of rubber is $3.8467 \times 10^{5} \mathrm{~mm}^{2}$. The covering rubber on the circumferential surface is neglected.

The rubber bearing has 30 sheets of rubber separated by 29 steel plates. The thickness of each rubber sheet is $4.0 \mathrm{~mm}$, while the thickness of each steel plate is $3.1 \mathrm{~mm}$. The total heights of rubber sheets and steel plates are $89.9 \mathrm{~mm}$ and $41.0 \mathrm{~mm}$, respectively, which lead to the total height $230.9 \mathrm{~mm}$ combining the rubber and steel. The steel plates, called flange, with radius $500 \mathrm{~mm}$ and thickness $28 \mathrm{~mm}$ are attached at the top and bottom of the rubber bearing.

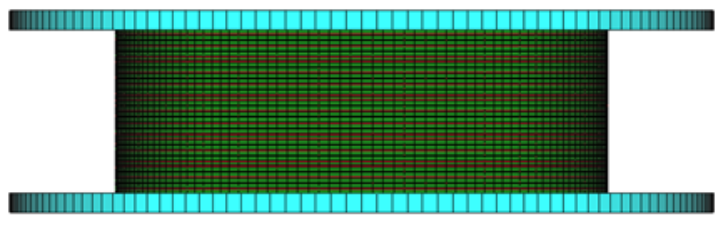

(a)

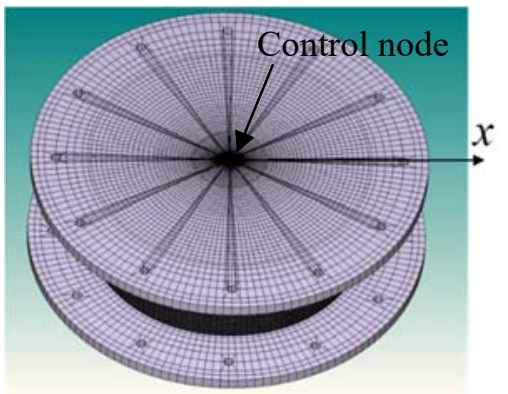

(c)

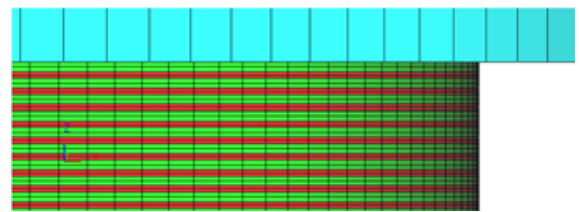

(b)

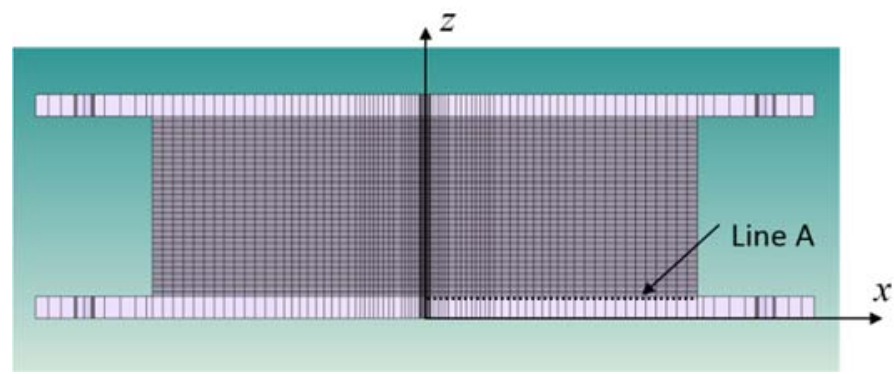

(d)

Figure 1. FE-mesh of a rubber bearing model; (a) side view, (b) close view of upper left, (c) diagonal view, (d) section in the $x z$-plane.

Each rubber sheet as well as steel plate is discretized into two layers of fully integrated eight-node linear hexahedral elements with eight integration points. The number of nodes is 502,981 including a control node, which is defined in Figure 1 and explained in Section 4.1. The number of elements is 486,240 including the rigid beams. The total number of degrees of freedom is $1,525,002$. Geometrical nonlinearity is incorporated using the updated Lagrangian formulation.

The Ogden model [26], which is categorized as hyper-elastic material, is used for the natural rubber. The strain energy density function is defined as

$$
U=\sum_{n=1}^{2} \frac{\mu_{n}}{\alpha_{n}}\left(\bar{\lambda}_{1}^{\alpha_{n}}+\bar{\lambda}_{2}^{\alpha_{n}}+\bar{\lambda}_{3}^{\alpha_{n}}-3\right)+4.5 K\left(J^{\beta}-1\right)^{2}
$$

where the bulk modulus $K$ is $1000 \mathrm{MPa}$, and other model parameters are $\alpha_{1}=1.6, \alpha_{2}=6.2$, $\mu_{1}=0.41 \mathrm{MPa}, \mu_{2}=0.0012 \mathrm{MPa}$, and $\beta=1 / 3$, which have been identified in Ref. [44] from the shear stress-strain relations of the experiments of a rubber bearing with various pressure levels. The variables $\bar{\lambda}_{1}, \bar{\lambda}_{2}$, and $\bar{\lambda}_{3}$ are the deviatoric stretches (principal values of right stretch tensor), and $J$ is the elastic volume ratio. Hence, the initial shear modulus is 
calculated as $G=\alpha_{1} \mu_{1}+\alpha_{2} \mu_{2}=0.66344 \mathrm{MPa}$, and Poisson's ratio is $(3 K / G-2) /(6 K / G-2)=0.49989$. The mass density of rubber is $2.00 \times 10^{3} \mathrm{~kg} / \mathrm{m}^{3}$. The steel is assumed to be elastoplastic with Young's modulus 205.0 GPa, Poisson's ratio 0.3, yield stress $235.0 \mathrm{MPa}$, linear kinematic hardening coefficient $205.0 \mathrm{MPa}$, and mass density $7.86 \times 10^{3} \mathrm{~kg} / \mathrm{m}^{3}$.

\section{BASE-ISOLATED FRAME MODEL}

Consider a 10-story frame as shown in Figure 2. The frame is supported by two rubber bearings that have the geometry and material properties described in Section 2. The distance between the centers of two rubber bearings is $7000 \mathrm{~mm}$, and the story height is $3500 \mathrm{~mm}$. The global coordinates are defined as shown in Figure 2(a), where the $y$-axis is perpendicular to the $x z$-plane, which is located in the center of the frame. The upper frame consists of RC columns and beams, which are assumed to remain in elastic range, where Young's modulus is 24.0 GPa, Poisson's ratio is 0.2 , and mass density is $2.3 \times 10^{3} \mathrm{~kg} / \mathrm{m}^{3}$.

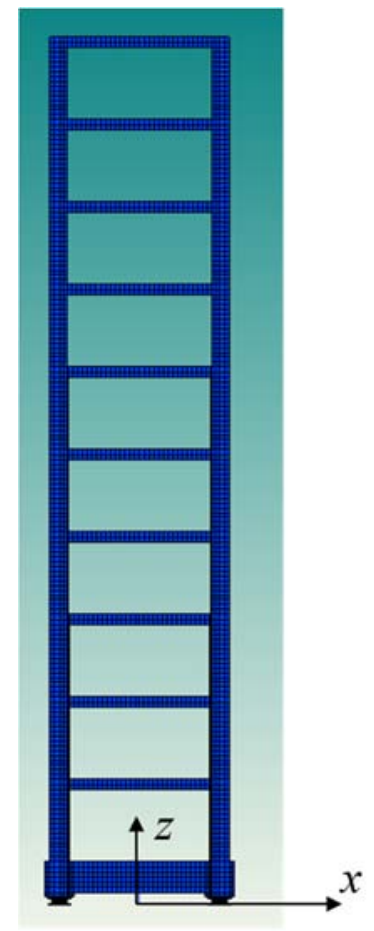

(a)

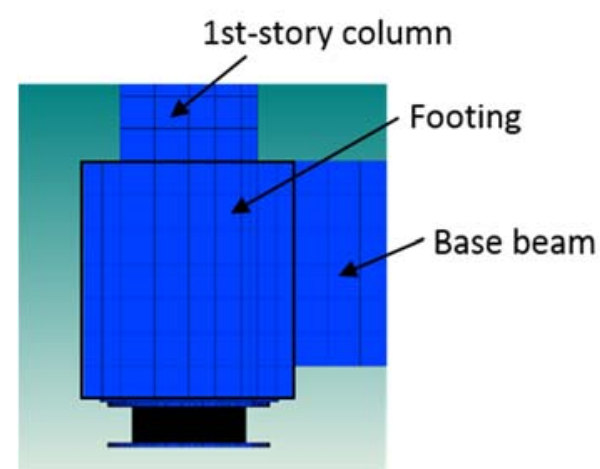

(b)

Figure 2. A 10-story base-isolated frame model: (a) elevation, (b) details at column base.

The member sections are listed in Table 1. The size of each footing at the intersection of the base beam and the 1st-story column is $1300 \mathrm{~mm}$ in $x$ - and $y$-directions with the height $1500 \mathrm{~mm}$. A $1100 \times 1100 \mathrm{~mm}$ square steel plate with thickness $30 \mathrm{~mm}$ is placed between the footing and the upper flange of the rubber bearing. In the FE-model, the square plate is connected with the upper surface of the upper flange and the lower surface of the footing using multi-point constraints (MPCs). Note that all members of the frame have threedimensional property although we investigate in-plane (xz-plane) response. Thus, the out-ofplane ( $y$-directional) displacements of nodes on the $x z$-plane of symmetry are constrained. The members of upper frame are also discretized into solid elements. Although beam elements are implemented in the recent version of the E-Simulator, the post-processing software for beam 
M. Ohsaki et al.

elements is under development. Therefore, we use solid elements for the frame members. The total numbers of nodes, elements, and DOFs are 1,047,157, 999,680, and 3,141,471, respectively. Note that the number of elements for the frame members is 27,212 , which is about $2.7 \%$ of the total number of elements including the rubber bearings. Hence the total number of elements will be reduced only slightly even if beam elements are used.

Table 1. List of member sections.

\begin{tabular}{cccc}
\hline \multicolumn{2}{c}{ Column } & \multicolumn{2}{c}{ Beam } \\
\hdashline Story & Size $(\mathrm{mm})$ & Floor & Size $(\mathrm{mm})$ \\
\hline $7-10$ & $750 \times 750$ & $7-$ Roof & $450 \times 750$ \\
$4-6$ & $800 \times 800$ & $4-6$ & $450 \times 800$ \\
\hdashline $1-3$ & $850 \times 850$ & $2-3$ & $450 \times 850$ \\
\hline & & Base & $700 \times 1300$ \\
\hline
\end{tabular}

The weight of RC frame including the footing and the base beam is $1741 \mathrm{kN}$, and the total weight including the two rubber bearings is $1755 \mathrm{kN}$. In order to incorporate the loads due to the weights of slabs and walls as well as the live load, the mass density of beams and columns are scaled by a factor 6.0, which leads to the total weight $10460 \mathrm{kN}$ and the mean vertical pressure $13.41 \mathrm{MPa}$ on the rubber bearing.

\section{STATIC ANALYSIS OF RUBBER BEARING}

We first carry out a series of static analyses for a layered plate as shown in Figure 3 to investigate dependency of shear responses on aspect ratios of elements, where steel and rubber materials are indicated by green and blue, respectively, which have the total heights 8 $\mathrm{mm}$ and $4 \mathrm{~mm}$, respectively. A loading node is added at the center of top surface, and it is connected to all nodes on the top surface using MPCs. All nodes in the bottom surface is fixed in three directions. A forced horizontal displacement of $24 \mathrm{~mm}$ is given at the loading node with fixed rotational components after application of vertical pressure of 14.0 MPa. The parameter $\beta$ in Eq.(1) is 1.0 for comparison with ABAQUS [45]. The load-displacement relation is shown in Table 2 for models with various number of horizontal divisions and aspect ratios, where the number of vertical division is six for all models. Note that the maximum aspect ratio of the elements of the rubber bearing model in Figure 1 is 14.4.

As seen from Table 2, the load-displacement relation is insensitive to the aspect ratios of elements. The same analysis processes are carried out using ABAQUS with the same material model and parameters. The horizontal reaction forces at the final step are shown in the last row of Table 2. As seen from the table, results of ABAQUS are close to those of ADVENTURECluster, and are also insensitive to the number of mesh division.

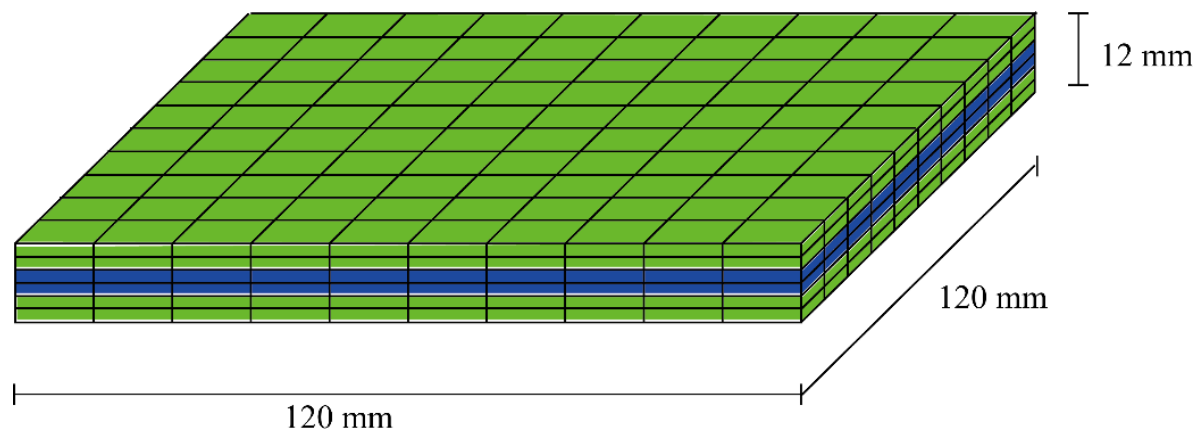

Figure 3. Layered plate for verification of mesh dependency. 
M. Ohsaki et al.

Table 2. Shear responses of layered plate subjected to vertical pressure and shear deformation.

\begin{tabular}{r|r|rrrrr}
\hline No. of division & 30 & 15 & 8 & 6 & 4 \\
\hline Aspect ratio & 2 & 4 & 7.5 & 10 & 15 \\
\hline & 0 & 0 & 0 & 0 & 0 & 0 \\
& 2.4 & 2825 & 2826 & 2826 & 2826 & 2826 \\
& 4.8 & 5523 & 5523 & 5524 & 5524 & 5524 \\
& 7.2 & 8376 & 8377 & 8378 & 8378 & 8379 \\
& 9.6 & 12253 & 12255 & 12256 & 12257 & 12258 \\
& 12 & 18760 & 18761 & 18763 & 18764 & 18765 \\
& 14.4 & 30480 & 30481 & 30483 & 30484 & 30486 \\
& 16.8 & 51261 & 51263 & 51266 & 51266 & 51269 \\
& 19.2 & 86510 & 86513 & 86517 & 86518 & 86522 \\
& 21.6 & 143452 & 143457 & 143463 & 143466 & 143471 \\
& 24 & 231318 & 231327 & 231337 & 231341 & 231348 \\
\hline ABAQUS & 24 & 234370 & 234380 & 234390 & 234410 & 234390 \\
\hline
\end{tabular}

We next carry out cyclic static analysis of a single rubber bearing in Figure 1 to investigate its mechanical properties. The lower surface of the bottom flange is fixed, and the control node is placed at the center of the upper surface of the upper flange. The control node is connected to the nodes on the flange by rigid beams are represented by MPCs as shown in Figure 1. Rotations along three axes of the control node are fixed. The self-weight is first applied, and vertical pressure of $14.0 \mathrm{MPa}$ corresponding to the nominal compressive force is next applied.

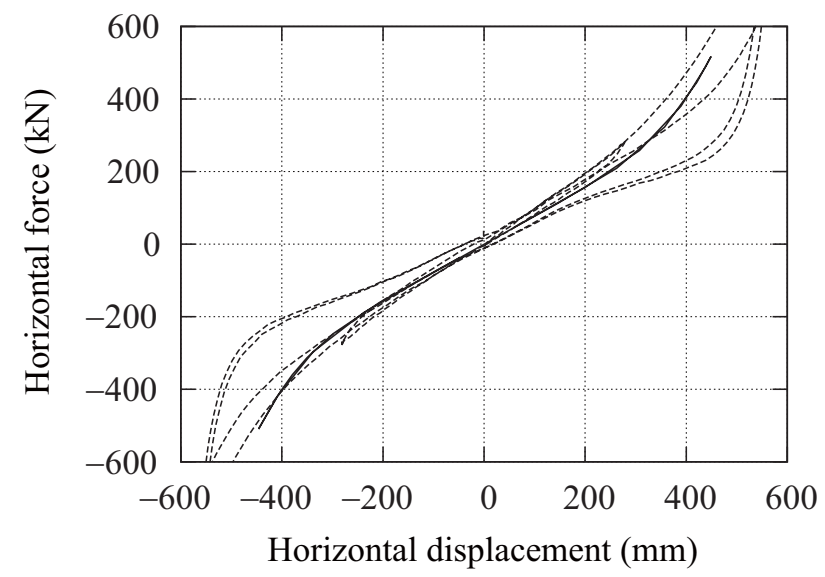

Figure 4. Relation between horizontal force and displacement under pressure of 14.0 MPa; solid line: numerical result, dashed line: experimental result [45].

Finally, a forced cyclic horizontal displacement is assigned at the control node in $x$ direction defined in Figure 1. The history of displacement $(\mathrm{mm})$ is given as $0 \rightarrow 450 \rightarrow 0 \rightarrow$ $-450 \rightarrow 0$, which is divided into 25 incremental steps. Since the total height of rubber is 141 $\mathrm{mm}$, the maximum displacement $450 \mathrm{~mm}$ corresponds to the mean shear strain of $319 \%$. Relation between the horizontal force and displacement is plotted in solid line in Figure 4. The maximum force at $450 \mathrm{~mm}$ is $517.47 \mathrm{kN}$. The curve is close to the experimental result in Ref. [45], which is plotted in dashed line. Note that the experimental result has a loop due to the Mullins effect. Viscosity can be neglected, because the experiment is carried out quasistatically with very small loading velocity. The relation between horizontal and vertical 
displacements is plotted in Figure 5, which exhibits a nonlinear relation. The total computational time using 16 cores of dual Intel Xeon E5-2687W $3.10 \mathrm{GHz}$ processors is $13,487 \mathrm{sec}$. (3.75 hours); i.e., the average time for a single step is $539 \mathrm{sec}$. (8.99 minutes).

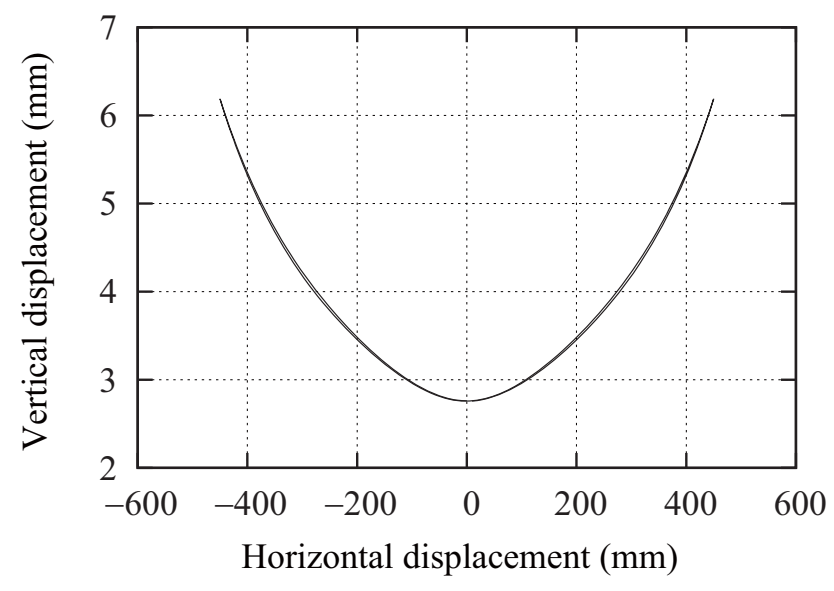

Figure 5. Relation between horizontal and vertical displacements under pressure of 14.0 MPa.

We also carried out the same analysis using a more precise model with four layers of hexahedral elements for each rubber sheet and steel plate. Although the aspect ratios of elements of four-layer model is worse than those of the two-layer models, the maximum force at $450 \mathrm{~mm}$ of the four-layer model is $517.45 \mathrm{kN}$, and there is no visible difference between the load-displacement relations of the models with two and four layers. Therefore, the twolayer model is assumed to simulate the responses with good accuracy, and it is used in next section for seismic response analysis of a base-isolated frame.

The vertical stresses evaluated at nodes at the maximum deformation are shown in Figure $6(a)$ in the $x z$-plane of symmetry. The nodal stress is evaluated as the average stress at each node among the elements connected to the node. Note that the elements with the same material, steel or rubber, are considered in this process of computing the average value. The non-uniform distribution of vertical stress can be clearly seen in Figure 6, where the values 50 and -50 MPa are the maximum and minimum values, respectively, of the color-bar.

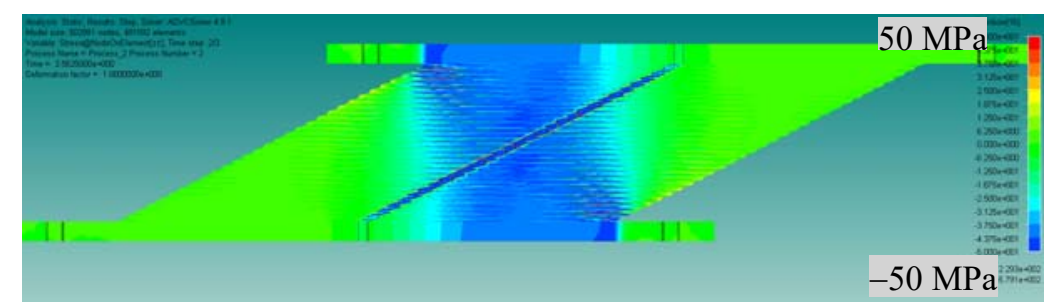

Figure 6. Average vertical stresses at nodes in the $x z$-plane of symmetry at maximum displacement.

Vertical stresses of rubber and steel in the xz-plane of symmetry are plotted in Figures 7(a) and (b), respectively. The stresses are evaluated along Line A, defined in Figure 1, at the bottom of the lowest rubber layer, and the line above Line A in the steel plate. It should be noted that the average stress among the integration points of each element, indicated by ' $\times$ ', has rather smooth distribution than the average stress at node, indicated by ' + '. Furthermore, the absolute value of stress at node is very large at the perimeter of rubber. The stresses of 
rubber and steel have similar distributions and the values except the center and perimeter are a little smaller than the mean pressure $57.85 \mathrm{MPa}$ computed using the overlapping area defined in Sec. 6 under deformation.

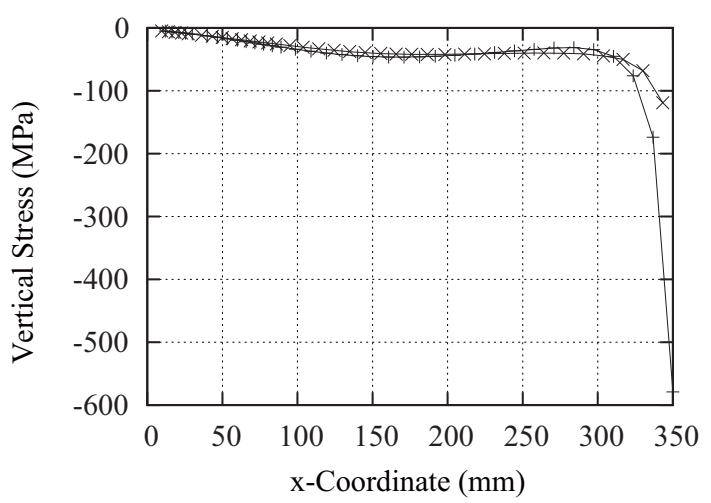

(a)

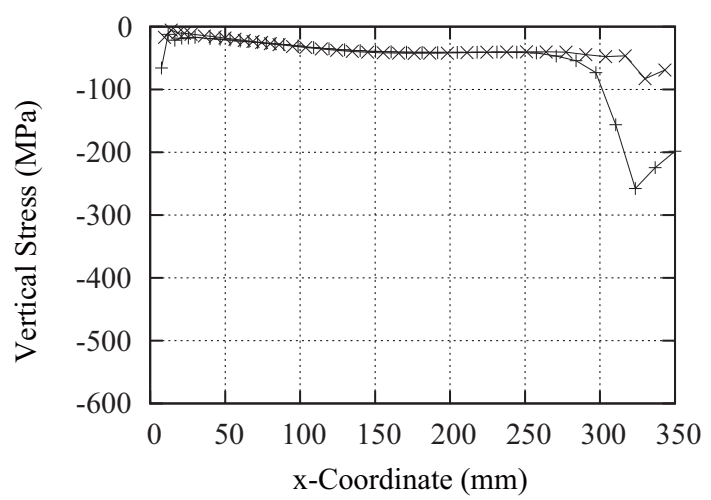

(b)

Figure 7. Distribution of vertical stress in the plane of symmetry; '+': stress evaluated at node, ' $x$ ': average stress at integration points of each element; (a) stress of rubber along Line A, defined in Figure 1, at the bottom of the lowest rubber sheet in the $x z$-plane of symmetry, (b) stress of steel along the line above Line A.

Figure 8 shows the distribution of vertical stress, at maximum deformation, on the upper surface of the top rubber sheet. It is confirmed from Figure 8 and also from Figure 6(a) that the vertical load is supported in a limited area that is the intersection of the upper and lower circle projected to the horizontal plane.

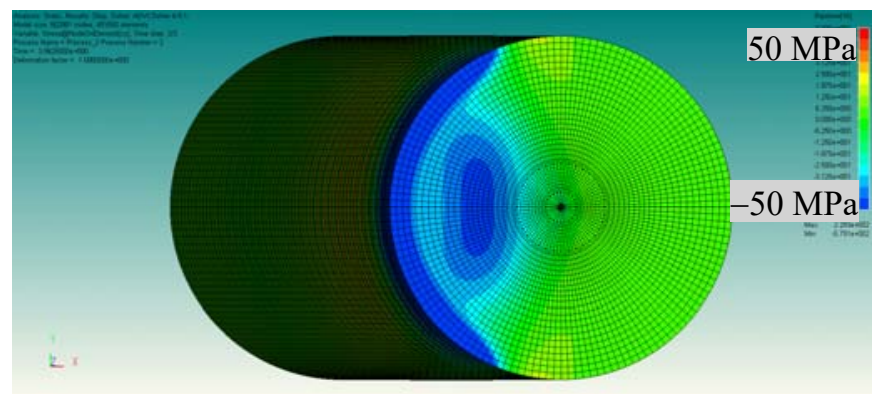

Figure 8 . Vertical stress on the upper surface of the top rubber sheet at maximum deformation.

\section{SEISMIC RESPONSE ANALYSIS OF BASE-ISOLATED FRAME}

Before carrying out seismic response analysis, horizontal stiffness of the base is evaluated by applying the horizontal static load incrementally as a body force that is equal to the mass density multiplied by incremental $x$-directional acceleration. The horizontal secant stiffness, computed from the base shear force divided by the displacements at each incremental step, is plotted in Figure 8 with respect to the mean value of horizontal displacement at the upper surfaces of the flanges of two rubber bearings. As seen from the figure, the stiffness increases, due to material nonlinearity, as displacement is increased. 


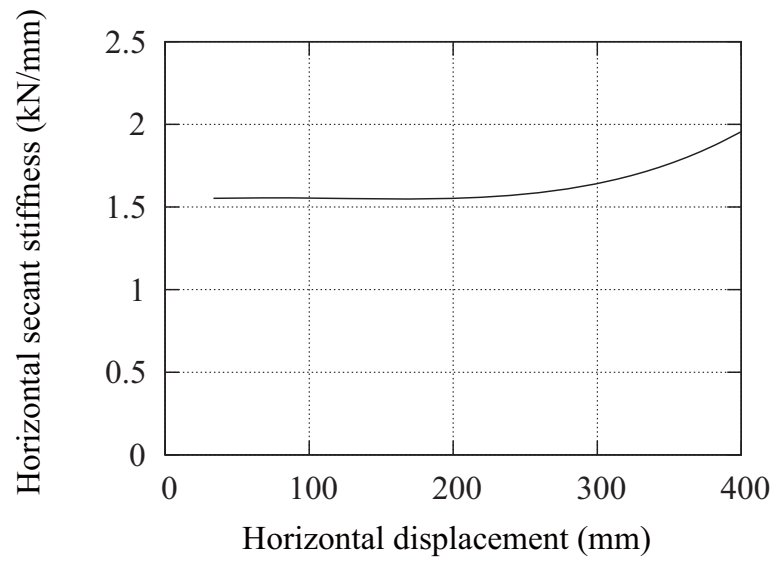

Figure 9. Relation between horizontal displacement and horizontal secant stiffness of the base.

A viscous damper is attached between the center of a base beam and the ground. We use the secant stiffness $1.77 \mathrm{kN} / \mathrm{mm}$ at displacement $350 \mathrm{~mm}$ in Figure 9 to compute the damping factor of the viscous damper. If we assume that the upper frame is a rigid body, then the first natural period is $4.784 \mathrm{~s}$, and the damping coefficient corresponding to the damping factor of 0.15 for the first mode is $412.1 \mathrm{~N} \cdot \mathrm{s} / \mathrm{mm}$. The stiffness proportional damping is used for the upper frame, although the deformation of upper frame is very small and its damping is negligible. The tangent stiffness matrix under the assumption that all materials are elastic is used for the calculation of the damping matrix. The coefficient for the matrix is computed so that the damping factor for the first mode is 0.03 .

After application of the self-weight of the frame, and dynamic time-history analysis is carried out to simulate seismic responses of the base-isolated frame. The frame is subjected to two Level-2 design ground motions called BCJ-L2 and AW-Kobe as shown in Figures 10(a) and (b), respectively. BCJ-L2 is distributed by the Building Center Japan. AW-Kobe is an artificial ground motion that is compatible to the design acceleration response spectrum specified according to the Notification 1461 of Ministry of Land, Infrastructure, Transport, and Tourism (MLIT), Japan, corresponding to the performance level of safety limit for the design based on Response and Limit Capacity Calculation. The phase of each frequency component is equal to that of the north-south component of the JMA Kobe record observed during the 1995 Kobe earthquake. We use the first 20 seconds of the waves.

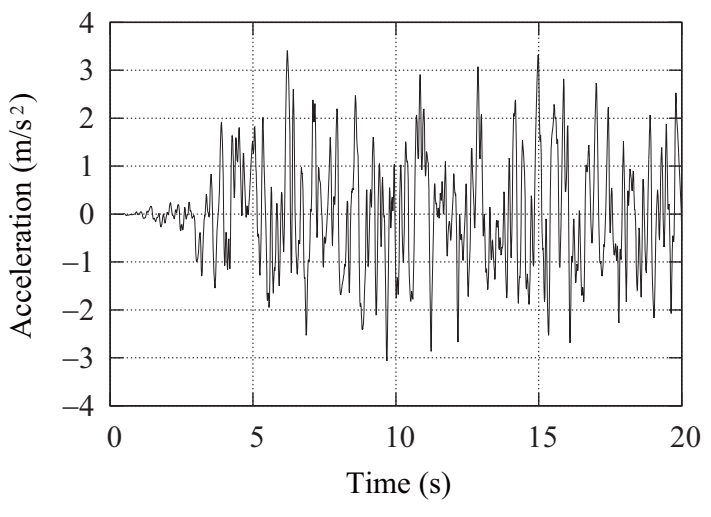

(a)

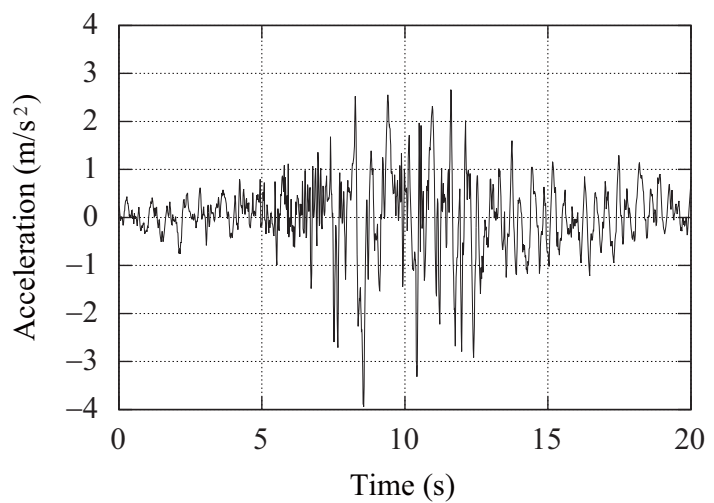

(b)

Figure 10. Seismic ground accelerations; (a) BCJ-L2, (b) AW-Kobe. 


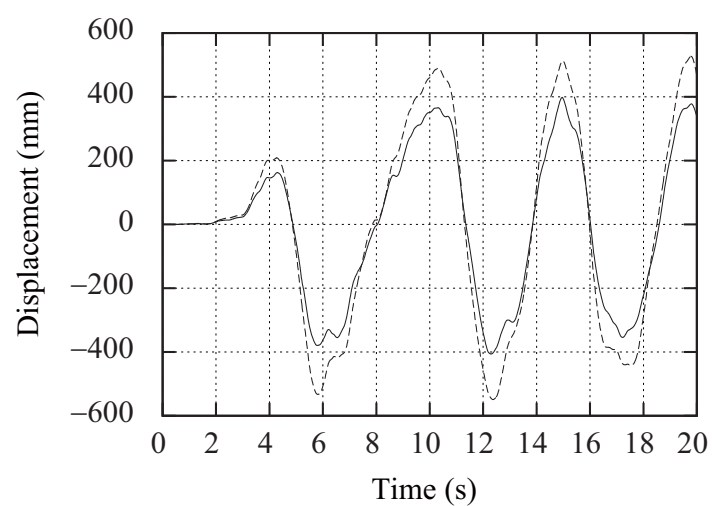

(a)

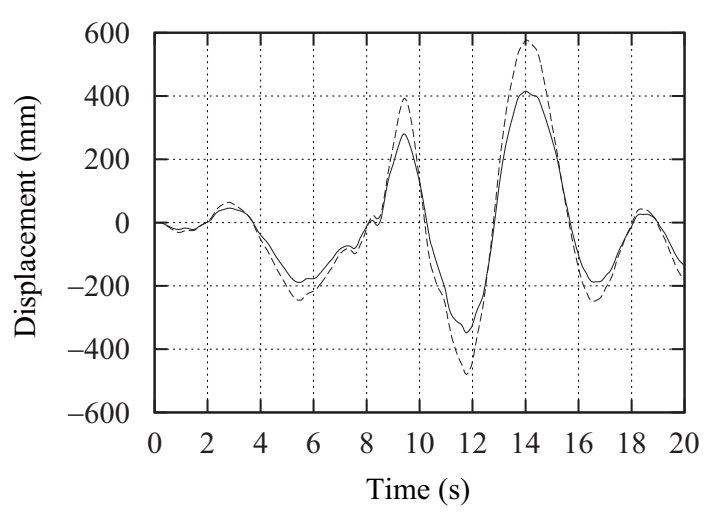

(b)

Figure 11. Displacement responses; solid line: upper surface of rubber bearing, dashed line: roof; (a) BCJ-L2, (b) AW-Kobe.

The initial time step for integration is $0.01 \mathrm{~s}$, which is automatically reduced, if necessary. The total computational time using 16 cores of dual Intel Xeon E5-2687W $3.10 \mathrm{GHz}$ processors is $1.5811 \times 10^{6} \mathrm{sec}$. (18 days and 7.19 hours) for 2,020 time steps including the initial static analysis for application of self-weight; therefore, the average time for a single step is 783 sec. (about 13.0 minutes). Figures 11(a) and (b) show the time histories of horizontal displacements under BCJ-L2 and AW-Kobe, respectively. The solid and dashed lines are the displacements at the upper surface of the rubber bearing and the roof of the frame, respectively. As observed in these figures, the deformation of the frame is small, and the frame moves like a rigid body with small rocking behavior. Since the response properties against these two seismic motions are very similar except the number of peaks of deformation, the detailed investigations of local responses are shown only for the BCJ-L2 wave.

The horizontal reaction force $R_{H}$ and vertical reaction force $R v$, which are computed as the sum of nodal reaction forces at the lower surfaces of the rubber bearings, are plotted in Figures 12 and 13, respectively. In Figure 12, the dotted line is the total horizontal force, and the solid and dashed lines are the values of $R_{H}$ of left and right supports, respectively.

We can see from Figures 12 and 13 that the absolute value of $R_{H}$ at the right support is larger than that of the left support, when the right support has smaller vertical reaction force $R_{V}$ than the left support. For example, the total value of $R_{H}$ at $t=12.30 \mathrm{~s}\left(U_{H}=406.22\right)$ is $805.86 \mathrm{kN}$. This total value is shared by $366.11 \mathrm{kN}$ at left and $439.74 \mathrm{kN}$ at right, which are different. This is because the values of $R_{V}$ at the left and right supports are $7548.7 \mathrm{kN}$ and $2885.2 \mathrm{kN}$, respectively, which correspond to the mean pressure $7548.7 / 0.38467 \times 10^{-3}=$ 19.624 MPa and $2885.2 / 0.38467 \times 10^{-3}=7.5005 \mathrm{MPa}$ with respect to the area of rubber. Note that the vertical pressure is $14.0 \mathrm{MPa}$ in Figure 3, and the value of $R_{H}$, computed by linear interpolation at $U_{H}=406.22 \mathrm{~mm}$, is $412.86 \mathrm{kN}$. The similar result is observed when the right support has a larger value of $R_{V}$ than the left support. This result confirms that the horizontal force-displacement relation depends on the pressure [46-48], and the difference in vertical pressure leads to the difference in $R_{H}$ value. It is seen from Figure 13 that the vertical reaction force is always positive; i.e., the rubber bearing does not exhibit tensile deformation, although local vertical stress may have positive value as presented below. 


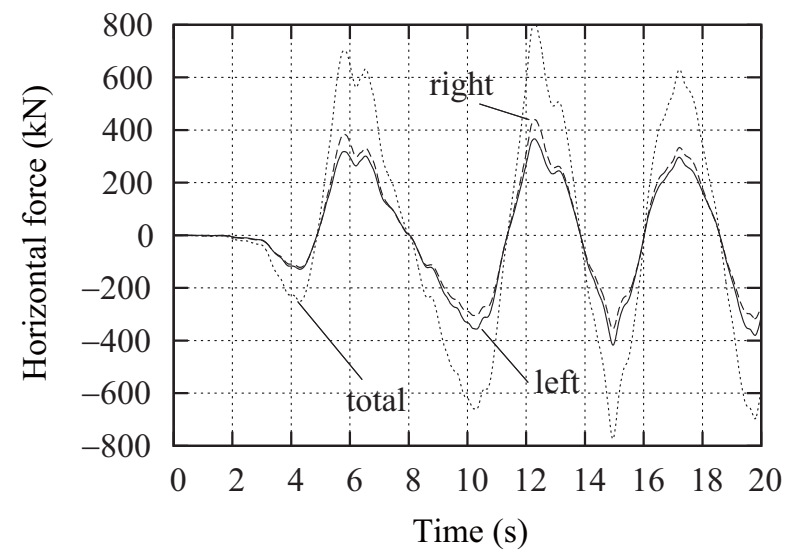

Figure 12. Horizontal reaction forces at fixed supports; solid line: left support, dashed line: right support, dotted line: total force.

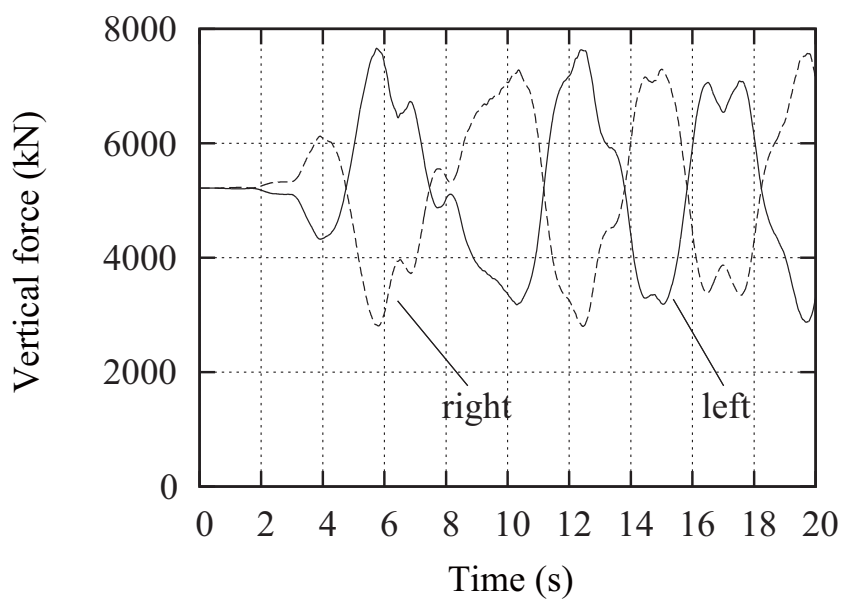

Figure 13. Vertical reaction forces at fixed supports; solid line: left support, dashed line: right support.

Although the phase difference between the displacements at the roof and the top surface of base is small as observed in Figure 11, the roof displacement is smoother and larger than the base displacement. Therefore, we investigate the rocking deformation of the frame. Let $D_{\mathrm{L}}$ and $D_{\mathrm{R}}$ denote the vertical displacements $(\mathrm{mm})$ of the center of top surfaces of the upper flanges of left and right bearings, respectively. The time history of rocking angle of the base beam, defined by $\left(D_{\mathrm{L}}-D_{\mathrm{R}}\right) / 7000$, is plotted in Figure 14. Although the angle is small, the maximum absolute value is $6.5329 \times 10^{-4} \mathrm{rad}$, which corresponds to the difference $4.5730 \mathrm{~mm}$ of the vertical displacements of the left and right bearings. Note that the angle of $6.5329 \times 10^{-4}$ rad is more than $10 \%$ of $1 / 200$ that is the allowable interstory drift angle against level-1 seismic motions. Furthermore, the displacement of the top surface of bearing due to the selfweight is $-2.7693 \mathrm{~mm}$. Since $2.7693>4.5730 / 2$, we can assume no tensile overall deformation occurs due to rocking of the frame. 


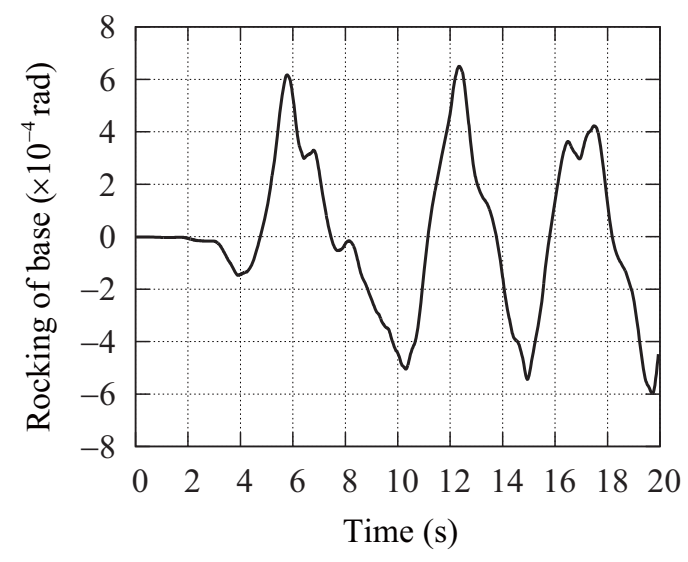

Figure 14. Time history of rocking angle of base beam.

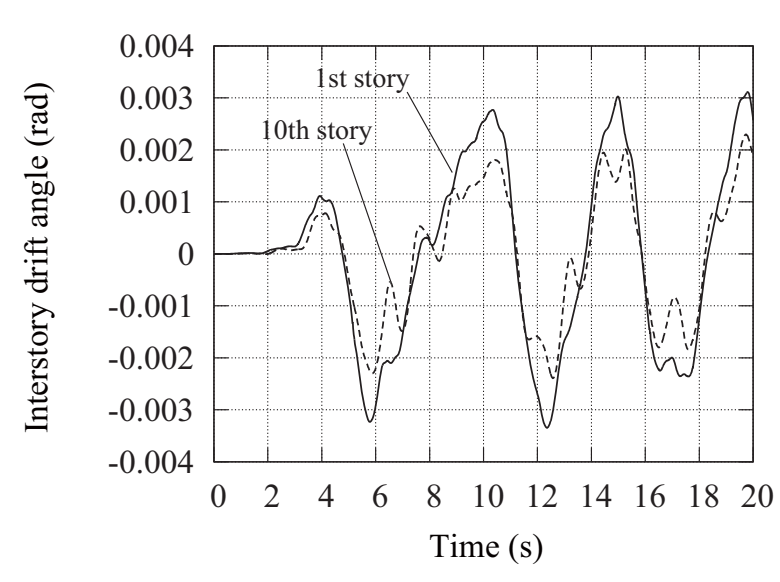

(a)

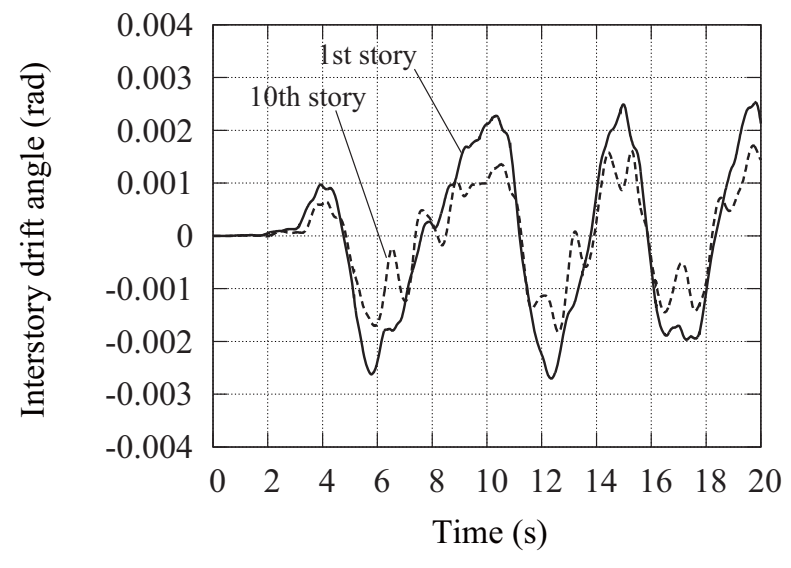

(b)

Figure 15. Time history of interstory drift angle; (a) drift angle including rocking angle, (b) net drift angle extracting rocking angle; solid line: 1st story, dashed line: 10th story.

The interstory drift angles of the 1st and 10th stories are plotted in solid and dashed lines, respectively, in Figure 15(a). Although the time histories of the phase are almost the same, more effect of higher modes are observed in the 10th story. Note that this property is different from that of the displacement response in Figure 11, where lower floor has more complex time history than upper floors. The net interstory drift angles after extracting the rockling angle are plotted in Figure 15(b). The effect of rocking is small; however, it is not negligibly small.

The maximum and minimum values of displacements and reaction forces are listed in Table 3, which shows that the maximum horizontal reaction force is about $6.66 \%$ of the total weight of the structure. Note that the maximum displacement of the roof relative to the top of the isolator is $149.72 \mathrm{~mm}$, which corresponds to a $0.406 \%$ drift angle. 
M. Ohsaki et al.

Table 3. Maximum and minimum values of displacements and reaction forces.

\begin{tabular}{|c|c|c|c|c|c|}
\hline & $\begin{array}{l}\text { Disp. of } \\
\text { upper surface } \\
\text { of bearing } \\
(\mathrm{mm})\end{array}$ & $\begin{array}{l}\text { Roof disp. } \\
\quad(\mathrm{mm})\end{array}$ & $\begin{array}{l}\text { Horizontal } \\
\text { reaction }(\mathrm{kN})\end{array}$ & $\begin{array}{l}\text { Vertical } \\
\text { reaction } \\
(\mathrm{left})(\mathrm{kN})\end{array}$ & $\begin{array}{c}\text { Vertical } \\
\text { reaction } \\
(\text { right })(\mathrm{kN})\end{array}$ \\
\hline $\begin{array}{l}\text { Maximum value } \\
\text { (Time }(\mathrm{sec}))\end{array}$ & $\begin{array}{l}397.82 \\
(14.96)\end{array}$ & $\begin{array}{l}526.78 \\
(19.78)\end{array}$ & $\begin{array}{l}806.16 \\
(12.29)\end{array}$ & $\begin{array}{r}7658.4 \\
(5.75)\end{array}$ & $\begin{array}{r}7568.5 \\
(19.74)\end{array}$ \\
\hline $\begin{array}{l}\text { Minimum value } \\
\text { (Time }(\mathrm{sec})\end{array}$ & $\begin{array}{r}-406.22 \\
(12.30)\end{array}$ & $\begin{array}{r}-549.13 \\
(12.37)\end{array}$ & $\begin{array}{r}-773.84 \\
(14.95)\end{array}$ & $\begin{array}{l}2871.8 \\
(19.69)\end{array}$ & $\begin{array}{l}2799.9 \\
(12.45)\end{array}$ \\
\hline
\end{tabular}

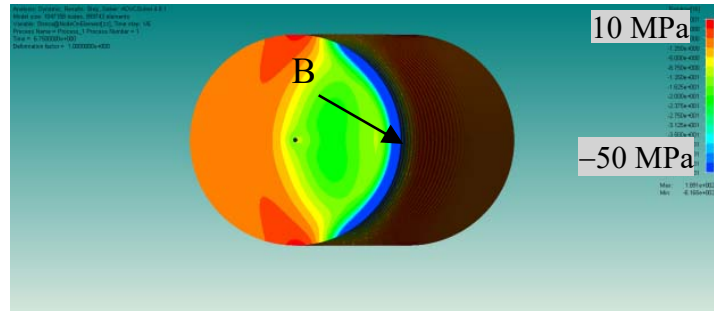

(a)

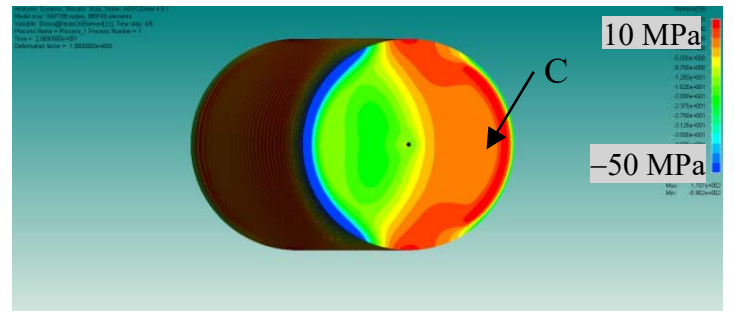

(b)

Figure 16. Vertical stress of left rubber bearing due to contact between upper flange and rubber; (a) maximum reaction at $t=5.75 \mathrm{~s}$, (b) minimum reaction at $t=19.69 \mathrm{~s}$.

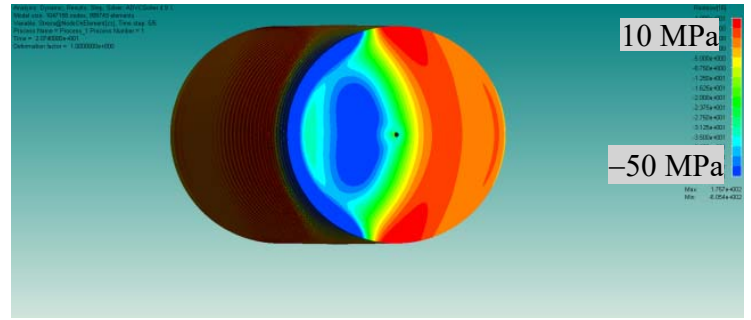

(a)

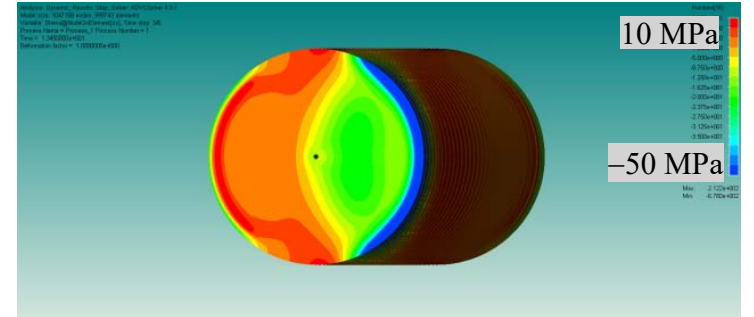

(b)

Figure 17. Vertical stress of right rubber bearing due to contact between upper flange and rubber; (a) maximum reaction at $t=19.74 \mathrm{~s}$, (b) minimum reaction at $t=12.45 \mathrm{~s}$.

Distributions of vertical stress due to contact between the upper flange and the rubber of the left bearing at $t=5.75 \mathrm{~s}$ and $19.69 \mathrm{~s}$, when the reaction takes the maximum and minimum values, respectively, are shown in Figure 16. We can confirm that the vertical stress is nonuniformly distributed on the contact surface. The maximum absolute value of vertical stress at $t=5.75 \mathrm{~s}$ is $559.64 \mathrm{MPa}$, which is very large; however, it is located at point $\mathrm{B}$ on the edge, and the maximum absolute values of vertical stresses at the second and third nodes from the edge are 188.34 and $80.238 \mathrm{MPa}$, respectively, which are less than the yield stress of steel. Similar figures for the right rubber bearing are shown in Figure 17.

Time history of the vertical stress at node $\mathrm{C}$ of the left rubber bearing, which is located at $39.72 \mathrm{~mm}$ from the perimeter as indicated in Figure 16(b), is plotted in Figure 18. As confirmed from the figure, vertical stress may have a positive (tensile) value, although the total vertical force of the rubber bearing is always compressive. Tensile stress is necessary to exist to equilibrate the unbalanced bending moment as noted by Konstantinidis et al. [47]. Furthermore, the peak tensile stress may be smaller if we consider the fact that the tensile stiffness of the natural rubber is smaller than the compressive stiffness [48]. Accordingly, tensile stress may be more widely distributed than the plots in Figures 16 and 17. 


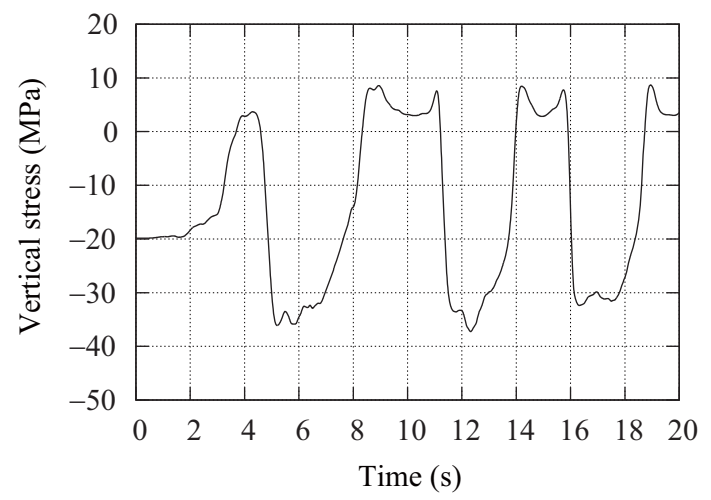

Figure 18. Time history of vertical stress at node $\mathrm{C}$ of left rubber bearing.

\section{FORCED-DISPLACEMENT ANALYSIS OF RUBBER BEARING}

Static monotonic analysis is carried out for detailed investigation of responses of a rubber bearing. After application of self-weight of the frame, forced horizontal displacements are assigned at the top of the flange linearly to the values at time $t=12.30 \mathrm{~s}$ of the seismic response analysis, when the base has the maximum horizontal deformation. Since the horizontal displacement at $t=12.30 \mathrm{~s}$ has a negative value, the left rubber bearing is analyzed under additional compressive deformation due to rocking of the upper frame. The forced horizontal (leftward) displacement $U_{H}$, vertical (downward) displacement $U_{V}$, and clockwise rotation $U_{R}$ are given as listed in Table 4. All displacement components, including rotation, are applied simultaneously. Let $\tau$ denote a parameter denoting the pseudo-time. The forced displacement is defined parametrically using $\tau$ as $\tau U_{H}, \tau U_{V}$, and $\tau U_{R}$, and $\tau$ is increased from 0 to 1 .

Table 4. Forced horizontal displacement $U_{H}$, vertical displacement $U_{V}$, and rotation $U_{R}$ at the top of flange.

\begin{tabular}{llll}
\hline & $\begin{array}{c}\text { Horizontal disp. } U_{H} \\
(\mathrm{~mm})\end{array}$ & $\begin{array}{c}\text { Vertical disp. } U_{V} \\
(\mathrm{~mm})\end{array}$ & $\begin{array}{c}\text { Rotation } U_{R} \\
(\mathrm{rad})\end{array}$ \\
\hline Self weight & 0.23422 & 2.8049 & 0.00022574 \\
Seismic load & 406.25 & 7.9573 & -0.0017196 \\
\hline
\end{tabular}

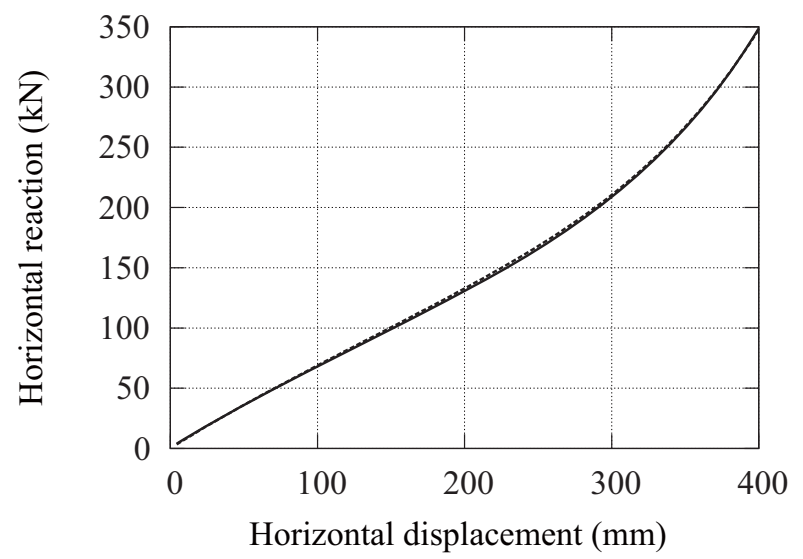

Figure 19. Relation between horizontal reaction force $R_{H}$ and horizontal displacement obtained by forced-displacement static analysis of a rubber bearing; solid line: with rotation, dashed line: without rotation. 
The horizontal reaction force $R_{H}$ is plotted with respect to $U_{H}$ in Figure 19. The value of $R_{H}$ at $U_{H}=406.25 \mathrm{~mm}$ is $361.42 \mathrm{kN}$. Note that $R_{H}$ of the left support at $U_{H}=406.25 \mathrm{~mm}$ in seismic response analysis is $366.11 \mathrm{kN}$.

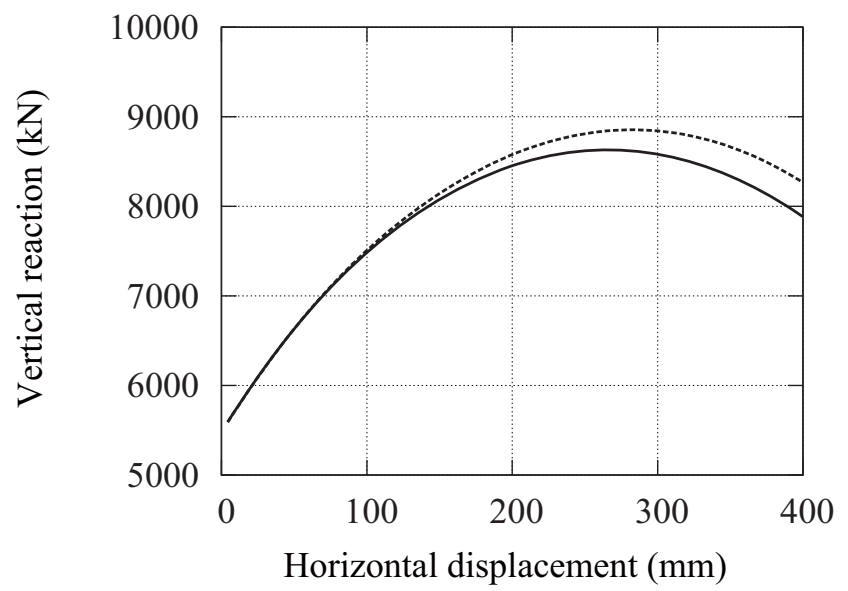

Figure 20. Relation between vertical reaction force $R_{V}$ and horizontal displacement obtained by forced-displacement static analysis of a rubber bearing; solid line: with rotation, dashed line: without rotation.

Relation between the vertical reaction force $R_{V}$ and $U_{H}$ is shown in solid line in Figure 20 . Note that $R_{V}$ has the maximum value before reaching the maximum horizontal displacement. This fact corresponds to the nonlinearity of the relation between $U_{H}$ and $U_{V}$ in Figure 5 under constant pressure. Therefore, the maximum value of $R V$ may be overestimated if it is evaluated by a forced-displacement analysis with constant ratio between $U_{H}$ and $U_{V}$.

The vertical contact stress between the lower face of the upper flange and the rubber sheet has a similar distribution as that of the seismic response in Figure 16. Figure 21(a) shows the variation of vertical stress at node B indicated in Figure 16(a), which has the maximum value among the nodes except those on the perimeter. We define the overlapping area [37], as shown in Figure 22, as the area of the compression core [35], which is the intersection of the circles of upper face of the top rubber sheet and the lower face of the bottom rubber sheet at each deformed state. The ratio of vertical stress at node B to the average vertical stress is called peak stress ratio. The peak stress ratio in which the average stress is defined with respect to the overlapping area is plotted in solid line in Figure 21(b). Note that if the peak stress ratio is larger than 1.0, the stress at node B is larger than the averaged stress. As seen from the figure, the peak stress ratio varies between 0.7 and 2.1, while it has larger value, as shown in solid line in Figure 21(c), if the average stress with respect to the total area of a rubber sheet is used. Note that the peak stress ratio with respect to the overlapping area approaches 1.0, which means that the almost all vertical force in a large deformation range is supported by the rubber in the overlapping area. Figure 23 shows distribution of vertical stress in the sections with different $y$-coordinates. 
M. Ohsaki et al.

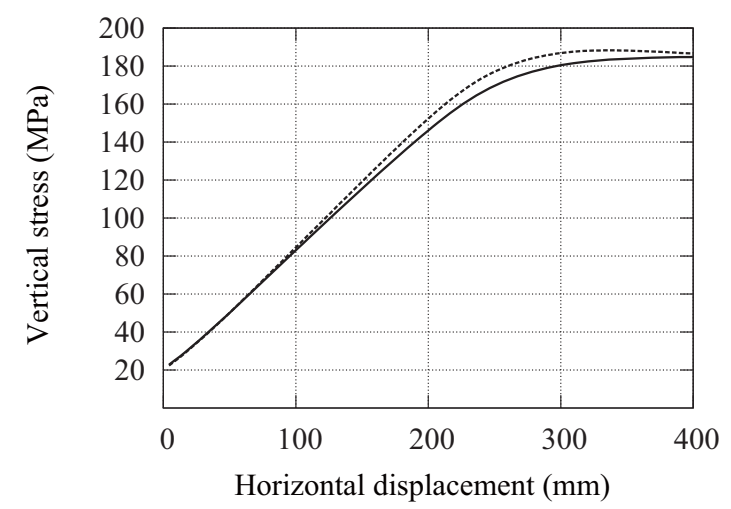

(a)

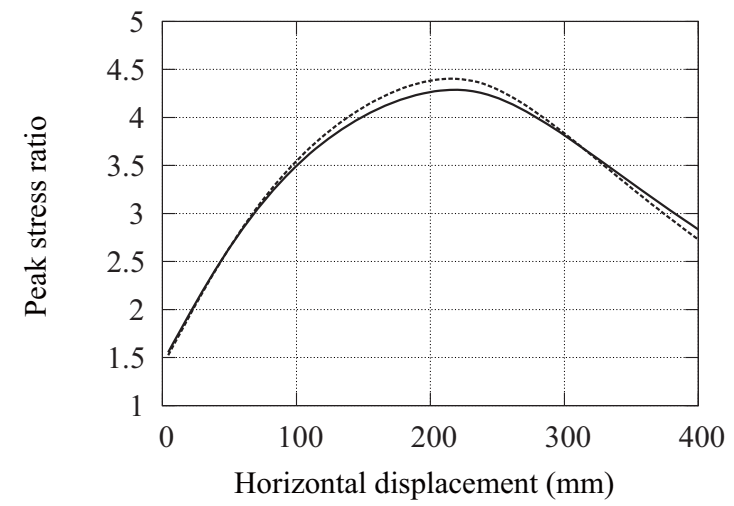

(b)

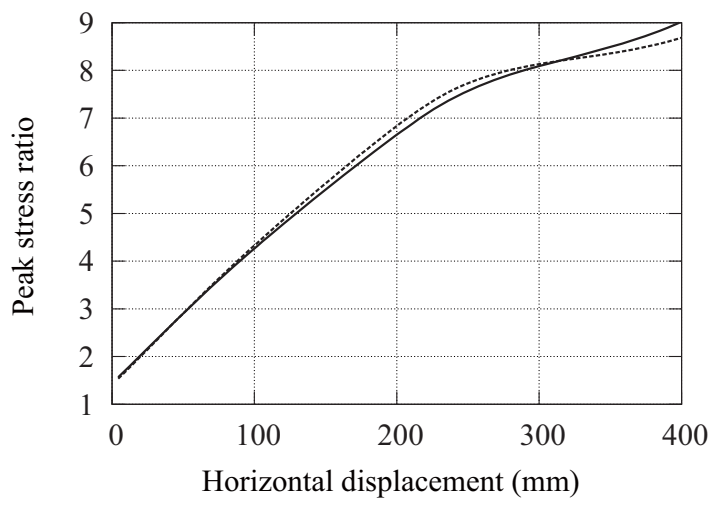

(c)

Figure 21. Variations of vertical stress and peak stress ratio evaluated at point B in Figure 15(a); (a) vertical stress, (b) peak stress ratio with respect to overlapping area, (c) peak stress ratio with respect to total area; solid line: with rotation, dashed line: without rotation.

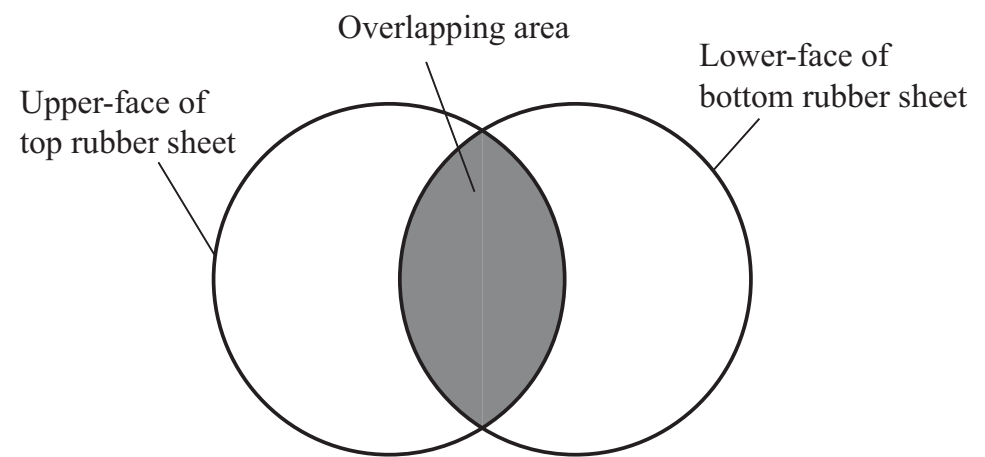

Figure 22. Definition of overlapping area.

We next carry out forced-displacement static analysis without rotation; i.e., the rotation $U_{R}$ in Table 4 is fixed at 0 throughout the analysis steps. The results are shown in dashed lines in Figures 19, 20, and 21. By fixing the rotation at 0 , the maximum vertical stress at node $\mathrm{B}$ increases $1.8 \%$ from $184.86 \mathrm{MPa}$ to $188.25 \mathrm{MPa}$; the maximum peak stress ratio with respect to the overlapping area increases $2.7 \%$ from 4.287 to 4.403 .

The maximum vertical displacement obtained by analysis with rotation is $7.9573 \mathrm{~mm}$, and the total height of rubber sheets is $141.0 \mathrm{~mm}$. Therefore, the average vertical strain is 7.9573 / $141.0=0.056435$. Since the maximum rotation for the analysis with rotation is $0.0017196 \mathrm{rad}$, as shown in table 4 , the contribution of rotation to the vertical strain, e.g., at the point with the 
distance $141.0 \mathrm{~mm}$ from the center is $0.0017196 \times 141.0 / 7.6460=0.030471$, which is very small.

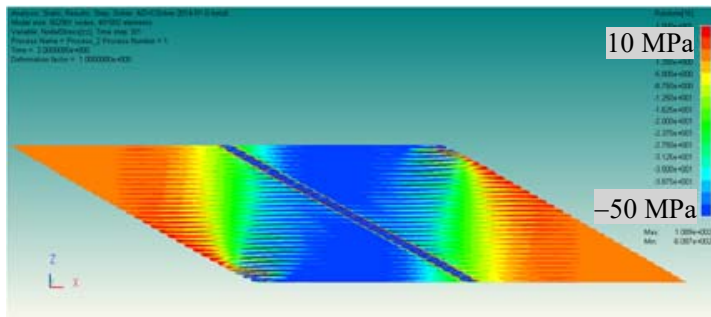

(a)

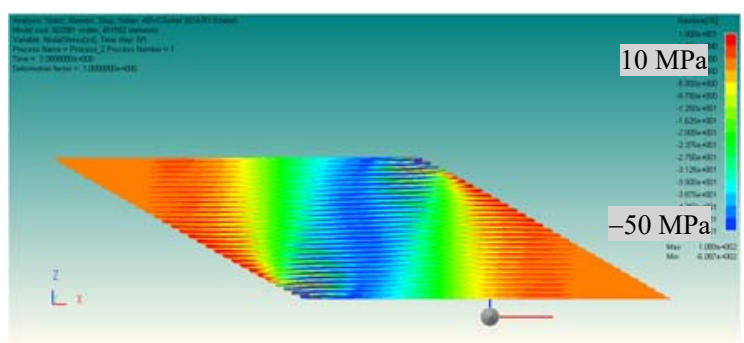

(c)

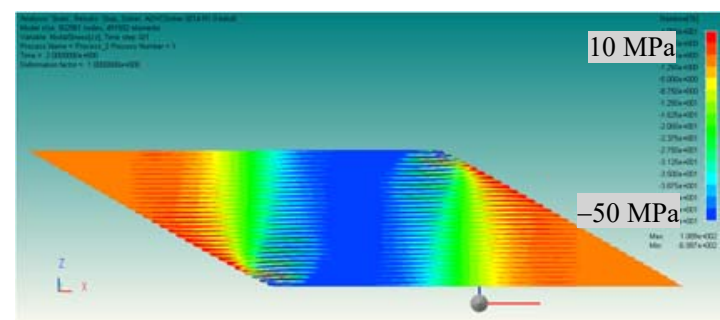

(b)

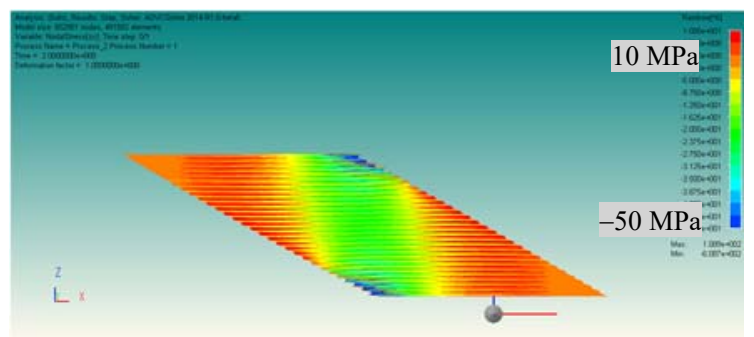

(d)

Figure 23. Distribution of vertical stress in the sections with different $y$-coordinates; (a) $y=0$, (b) $y=100 \mathrm{~mm}$, (c) $y=200 \mathrm{~mm}$, (d) $y=300 \mathrm{~mm}$.

\section{CONCLUSIONS}

Detailed FE-analyses have been carried out for investigating static and dynamic properties of rubber bearings attached to a 10-story frame. The conclusions drawn from this study are summarized as follows:

1. Large-scale FE-analysis enables us to investigate simultaneously the time histories of global and local responses of a base-isolated building frame subjected to seismic motions. The responses of frame members and laminated rubber bearings can be simulated precisely using an FE-model as an assemblage of about 3 million hexahedral solid elements. The computational time for time-history analysis of FE-model of a frame with more than 3 million DOFs remains in a practically admissible range using a single PC with 16 cores.

2. Time histories of interaction between the frame and base isolators should be incorporated to accurately evaluate the seismic response of the base-isolated frame. The interaction through rocking of the rubber bearing leads to non-uniform and possibly tensile vertical stress at the upper surface. Difference between the tensile and compressive stiffnesses of rubber material should be incorporated for more accurate estimation of distribution of tensile stress.

3. Since the horizontal reaction force strongly depends on the vertical pressure, which varies during seismic excitation, the horizontal forces of rubber bearings of base-isolated structures have different values even under the same horizontal displacement, if the variation of vertical force due to rocking of the frame is considered.

4. The vertical stress may be overestimated if the rocking of upper flange is not appropriately incorporated in the static analysis. Furthermore, the vertical stress nonlinearly depends on the horizontal displacement; therefore, it may be overestimated if the ratio between vertical and horizontal displacements is not accurately assigned during the forced-displacement 
static analysis.

It should be noted here that it is difficult to measure the local internal responses of a rubber bearing in a shake-table test. Therefore, FE-analysis will be an indispensable tool for analysis and design of laminated rubber bearings. Incorporation of damping, softening property, and effect of temperature change for lead and high-damping rubber bearings remains to be investigated in future research.

\section{ACKNOWLEDGEMENTS}

This study is a part of E-Defense Seismic Experimental Study and Simulation System Development Project conducted by E-Simulator Production Committee (Leader: Prof. Muneo Hori, The University of Tokyo). The authors acknowledge the valuable contribution from the committee members, and the financial support by NIED. The contribution by Dr. Tomonobu Ohyama and Mr. Kiyoshi Yuyama at Allied Engineering Corporation for computation and mesh generation is also acknowledged.

\section{REFERENCES}

1. Allied Engineering Corporation. http://www.alde.co.jp/english/advc/index.html [January 14, 2015].

2. Akiba $\mathrm{H}$ et al. Large scale drop impact analysis of mobile phone using ADVC on blue gene/L. Proceedings of the International Conference for High Performance Computing Networking and Storage (SC06), Tampa, FL, 2006; Paper No. 46.

3. Suzuki M, Ohyama T, Akiba H, Yoshimura S, Noguchi H. Development of fast and robust parallel CGCG solver for large scale finite element analyses. Trans. Japan Society of Mechanical Engineers 2002:A68:1010-1017. (in Japanese)

4. Akiba H, Ohyama T, Shibata Y. CGCG method for structural analysis and its enhancement. Proc. 7th Int. Conf. Eng. Computational Technology (ECT2010) 2010, Valencia, Spain.

5. Ohsaki M, Miyamura T, Kohiyama M, Hori M, Noguchi H, Akiba H, Kajiwara K, Ine T. High-precision finite element analysis of elastoplastic dynamic responses of superhighrise steel frames. Earthquake Engineering and Structural Dynamics 2009; 38(5):635-654.

6. Miyamura T, Ohsaki M, Kohiyama M, Isobe D, Onda K, Akiba H, Hori M, Kajiwara K, Ine T. Large-Scale FE Analysis of Steel Building Frames Using E-Simulator. Progress of Nuclear Science and Technology 2011; 2:651-656.

7. Miyamura T, Yamashita T, Akiba H, Ohsaki M. Dynamic FE simulation of four-story steel frame modeled by solid elements and its validation using results of full-scale shake-table test. Earthquake Eng. Struct. Dyn. (accepted for publication)

8. Yamashita T, Ohsaki M, Kohiyama M, Miyamura T, Zhang JY, Tagawa H. Detailed finite element analysis of composite beam under cyclic loads. J. Struct. Constr. Eng., Architectural Institute of Japan 2014;74:1481-1490. (in Japanese) 
9. Chang $\mathrm{CH}$. Modeling of laminated rubber bearings using an analytical stiffness matrix. International Journal of Solids and Structures 2002; 39:6055-6078.

10. Kelly JM, Takhirov SM. Tension buckling in multilayer elastomeric isolation bearings. Journal of Mechanics of Materials and Structures 2007; 2(8):1591-1605.

11. Iizuka M. A macroscopic model for predicting large-deformation behaviors of laminated rubber bearings. Engineering Structures 2000; 22:323-334.

12. Weitzmann R, Ohsaki M, Nakashima, M. Simplified methods for design of base-isolated structures in the long-period high-damping range Earthquake Engng. Struct. Dyn 2006;35:497-515.

13. Abe M, Yoshida J, Fujino Y. Multiaxial behaviors of laminated rubber bearings and their modeling, II: Modeling, Journal of Structural Engineering 2004; 130(8): 1133-1144.

14. Kalpakidis IV, Constantinos MC, Whittaker AS. Modeling strength degradation in leadrubber bearings under earthquake shaking. Earthquake Engineering and Structural Dynamics 2010; 39:1533-1549.

15. Yamamoto M, Minewaki S, Yoneda H, Higashino M. Nonlinear behavior of highdamping rubber bearings under horizontal bidirectional loading: full-scale tests and analytical modeling. Earthquake Engineering and Structural Dynamics 2012; 41(13): 1845-1860.

16. Takaoka E, Takenaka Y, Nimura A. Shaking table test and analysis method on ultimate behavior of slender base-isolated structure supported by laminated rubber bearings. Earthquake Engineering and Structural Dynamics 2010; 40:551-570.

17. Kikuchi M, Nakamura T, Aiken ID. Three-dimensional analysis for square seismic isolation bearings under large shear deformations and high axial loads. Earthquake Engineering and Structural Dynamics 2010; 39:1513-1531.

18. Kelly JM, Konstantinidis DA. Mechanics of Rubber Bearings for Seismic and Vibration Isolation 2011, Wiley.

19. Nagarajaiah S, Ferrell K. Stability of elastomeric isolation bearings. J. Struct. Eng., ASCE 1999;125(9):946-954.

20. Buckle I, Nagarajaiah S, Ferrell K. Stability of elastomeric isolation bearings: Experimental study. J. Struct. Eng., ASCE 2002;128(1):3-11.

21. Koh CG, Kelly JM. A simple mechanical model for elastmeric bearings used in base isolation. Int. J. Mech. Sci. 1988:30(12): 933-943.

22. Bergstrom JC, Boyce MC. Constitutive modelling of the large strain time-dependent behaviour of elastomers. Journal of Mechanics and Physics of Solids 1998; 46:931-954.

23. Bergstrom JC, Boyce MC. Large strain time-dependent behavior of filled elastomers. Mechanics of Materials 2000; 32:627-644.

24. Miehe C, Keck J. Superimposed finite elastic-viscoelastic-plastoelastic stress response with damage in filled rubbery polymers: Experiments, modelling and algorithmic Implementation. Journal of Mechanics and Physics of Solids 2000; 48:323-365.

25. Ogden RW, Roxburgh DG. A pseudo-elastic model for the Mullins effect in filled rubber. Proceedings of Royal Society of London Series A 1999; 455:2861-2878. 
26. Ogden RW. Large deformation isotropic elasticity, on the correlation of the theory and experiment for incompressible rubberlike solids. Proceedings of Royal Society of London Series A 1972; 328:567-583.

27. Matsuda A, Ohtori Y, Yabana S, Hirata K. Numerical simulation of the loading tests of laminated rubber bearings. JSME International Journal, Series A 2001; 44(1):160-166.

28. Gracia LA, Liarte E, Pelegay JL, Calvo B. Finite element simulation of the hysteretic behavior of an industrial rubber: Application to design of rubber components. Finite Elements in Analysis and Design 2010; 46(4):357-368.

29. Lejeunes S, Boukamel A, Cochelin B. Analysis of laminated rubber bearings with a numerical reduction model method. Archive of Applied Mechanics 2006; 76(56):311-326.

30. Ali HEM, Abdel-Ghaffar AM. Modeling of rubber and lead passive-control bearings for seismic analysis. Journal of Structural Engineering 1995; 121(7):1134-1144.

31. Hart-Smith LJ, Crisp JDC. Large elastic deformations of thin rubber membranes. International Journal of Engineering Science 1967; 5(1):1-24.

32. Matsuda A. Evaluation for mechanical properties of laminated rubber bearings using finite element analysis. Journal of Pressure Vessel Technology 2004; 126(2):134-140.

33. Cardone D, Gesualdi G, Nigro, D. Effects of air temperature on the cyclicbehavior of elastomeric seismic isolators. Bulletin of Earthquake Engineering 2011; 9:1227-1225.

34. Moon B, Kang G, Kang B, Kelly JM. Design and manufacturing of fiber reinforced elastomeric isolator for seismic isolation. Journal of Materials Processing Technology 2002; 131:145-150.

35. Toopchi-Nezhad H, Tait MJ, Drysdale, RG. Bonded versus unbonded strip fiber reinforced elastomeric isolators: Finite element analysis. Composite Structures; 2011; 93(2):850-859.

36. Osgooei PM, Tait MJ, Konstantinidis D. Finite element analysis of unbonded square fiber-reinforced elastomeric isolators (FREIs) under lateral loading in different directions. Composite Structures 2014; 113:164-173.

37. Warn GP, Weisman J. Parametric finite element investigation of the critical load capacity of elastomeric strip bearings. Engineering Structures 2011; 33:3509-3515.

38. Osgooei PM, Tait MJ, Konstantinidis D. Three-dimensional finite element analysis of circular fibre-reinforced elastomeric bearings under compression.. Composite Structures 2014; 108:191-204.

39. Mordini A, Stauss A. An innovative earthquake isolation system using fibre reinforced rubber bearings. Engineering Structures 2008; 33:2239-2751.

40. Das A, Dutta A, Deb SK. Performance of fiber-reinforced elastomeric base isolators under cyclic excitation. Structural Control and Health Monitoring; published online, DOI:10.1002/stc. 1668 .

41. Cardone D, Flora A, Gesualdi G. Inelastic response of RC frame building with seismic isolation. Earthquake Engineering and Structural Dynamics 2013; 42:871-889. 
42. Gur S, Mishra SK, Chakraborty S. Performance assesment of buildings isolated by shape-memory ally rubber bearing: Comparison with elastomeric bearing under nearfault earthquakes. Structural Control and Health Monitoring 2014; 21:449-465.

43. Salomón O, Oller S, Barbat A. Finite element analysis of base isolated buildings subjected to earthquake loads. International Journal for Numerical Methods in Engineering 1999;46:1741-1761.

44. Mori T, Murota N, Kudo M, Shimamoto R, Sato N, Takenaka Y. Mechanical characteristics of a two-tiered laminated rubber bearing for actuating large deformation: Part 4, Simulation analysis using an FEM model. Proceedings of Annual Meeting of Architectural Institute of Japan 2010; B-2:413-414. (in Japanese)

45. Dassault Systemes. ABAQUS User's Manual Ver. 6.132014.

46. Minewaki S, Yamamoto M, Higashino M, Hamaguchi H, Kyuke H, Sone T, Yoneda H. Performance tests of full size isolators for super high-rise isolated buildings. Journal of Structural Engineering, Architectural Institute of Japan 2009; 55B:469-477. (in Japanese)

47. Konstantinidis D, Kelly JM, Makris N. Experimental investigations on the seismic response of bridge bearings. Technical Report EERC-2008/02. Earthquake Engineering Research Center, University of California, Berkeley, 2008.

48. Yang QR, Liu WG, He WF, Feng DM. Tensile stiffness and deformation model of rubber isolators in tension and tension-shear states. Journal of Engineering Mechanics 2010; 136(4):429-437. 